\title{
Synthesis Nano Dendrimer Supramolecular with Melamine Core
}

\section{SAMANEH MAGHSOODI*, ABDOULHOSSIEN MASSOUDI and MOHAMMAD HAKIMI}

Department of Chemistry, Payam-e Noor University of Mashhad, Mashhad, Iran.

*Corresponding author E-mail: sam.maghsoodi@yahoo.com

http://dx.doi.org/10.13005/ojc/320618

(Received: June 01, 2016; Accepted: October 14, 2016)

\begin{abstract}
Dendrimers are a family of three-dimensional polymers and in nano dimension which are characterized by spherical structure. Excellent structural properties of dendrimers have distinguished them completely from linear polymers. Dendrimers have monodispersity characteristic and their size and molecular weight is controllable exactly during synthesis such as PAMAM dendrimers. Melamine can be used for synthetic core dendrimer through various methods including divergent. Melamine and related derivatives are able to form self-assembling compound via organized intramolecular networks of hydrogen bonds and provide useful molecular scaffolding components which are exploited by the field of supramolecular chemistry; which is beyond covalent bonding. In this study, the dendrimers of generated 0.5 and 1 with ester and primary amine-terminated groups with melamine and methyl acrylate were synthesized. The Synthesized dendrimer is able to form hydrogen bonding due to its nitrogen, oxygen and hydrogen atoms which was led to supramolecule characteristic. The reaction products were identified with $\mathrm{H}$ NMR, and ${ }^{13} \mathrm{C}$ NMR, FT-IR, MASS spectroscopic techniques. Also nano properties of the supramoleculs were determined by X-ray diffraction method. Supramolecular characteristics of synthesized dendrimer can be studied by shifts in H-NMR peaks and also flattening of FT-IR spectrum. The synthesized dendrimer derivatives are promising for environmental and medical applications. Also, such compounds might be reacting with transition metals as ligand and could be served as catalysts.
\end{abstract}

Keywords: Dendrimer, Hydrogen bond, Supramolecule, Melamine.

\section{INTRODUCTION}

The first dendrimers, named "cascade" molecules, were produced by Vögtle et al. in 1978'. Dendrimers are constructed in a stepwise manner through repeatable synthetic steps ${ }^{2}$. Each repetition cycle forms an additional layer of branches, called "generation"3,4. Two major synthetic approaches have appeared: the divergent approach in which growth starts from the inside (core) proceeding outwards, and the convergent approach proceeding "outsidein", by first creating "dendrons" which are coupled to the core ${ }^{5}$. Generally, synthetic chemists now have a considerable degree of control over the covalent synthesis of dendritic superstructures using a wide range of organic and inorganic methodologies ${ }^{6}$. 
Growing attention has turned to the production of dendritic structures using supramolecular synthetic methods in other words, synthesising dendrimers held together by non-covalent (or supramolecular) interactions ${ }^{7}$. Supramolecular chemistry lies beyond molecular chemistry based on the covalent bond and it is the chemistry of the entities generated via intermolecular noncovalent interactions ${ }^{8-10}$. These forces consist of hydrogen bonding, metal coordination, hydrophobic forces, van der Waals forces, pi-pi interactions and electrostatic effects ${ }^{11}$.<smiles>C=CC(=O)Oc1ccc(C)cc1</smiles>

The directionality and strength of the supramolecular bonding are significant features of systems that can be regarded as polymers and that behave based on well-established theories of polymer physics ${ }^{12,13}$. Three main categories of supramolecular polymers can be distinguished: coordination polymers, polymers formed via $\pi$ - $\pi$ stacking of the monomeric units, and hydrogen bonded polymers. Hydrogen bonding interactions are very useful for the construction of supramolecular polymers due to their strength, directionality and reversibility ${ }^{14}$. Both<smiles>COC(=O)CCNc1nc(NCCC(=O)OC)nc(NCCC(=O)OC)n1</smiles>

Fig.1: Synthesis of dendrimer $G_{0.5}$

(1) +<smiles>Nc1nc(N)nc(N)n1</smiles><smiles>Nc1cc(NC(=O)CCNc2nc(CCCC(=O)Nc3nc(N)cc(N)n3)nc(NCCC(=O)Nc3cc(N)nc(N)n3)n2)nc(N)n1</smiles>

Fig.2: Synthesis of dendrimer $G_{1}$ 
fully formed spherical dendrimers and individual dendritic branches (or dendrons) have been of the center of attention for their application in supramolecular dendrimer chemistry ${ }^{15}$. Melamine and related triazine derivatives have the ability to form self-assembling, high molecular weight compound via organized intramolecular networks of hydrogen bonds and ð-ð aromatic ring stacking ${ }^{16,17}$. The unique capabilities exhibited by melamine and related triazine derivatives present useful molecular scaffolding components employed by the field of supramolecular chemistry to produce a variety of sophisticated nano- or microscaled molecular compound ${ }^{18,19}$. In this article, a new melamine-based dendrimer is synthesized which its supramolecular and nano dimensions are studied.

\section{MATERIALS AND METHOD}

\section{Materials}

Melamine, methyl acrylate (Sigma- Alridch) were purified using distillation plant. Dimethyl sulfoxide (DMSO), methanol, sodium azide (Merck) were used for the synthesis.

\section{Equipments}

FT-IR analysis was performed using a SHIMADZU FTIR-8400S Spectrometer by $\mathrm{KBr}$ pellet technique. ${ }^{1} \mathrm{H}$ and ${ }^{13} \mathrm{C}$ NMR spectra were carried out on a Bruker AC $300 \mathrm{MHz}$ nuclear magnetic resonance (NMR) spectrometer. The MS system employed in this study consisted of 5973 Network Mass Selective Detector of Agilent Technology (HP).

\section{METHOD}

\section{Synthesis of dendrimers}

Synthesis of the dendrimer $G_{0.5}$ with ester terminated group

A solution of freshly distilled melamine $(5.0 \mathrm{~g})$ and sodium azide $(0.66 \mathrm{~g})$ in DMSO (50 $\mathrm{ml}$ ) was stirred for $1 \mathrm{~h}$ at $25^{\circ} \mathrm{C}$ and there was drop wised added over period of $2 \mathrm{~h}$ to a stirred solution of methyl acrylate $(10.78 \mathrm{ml})$ in DMSO $(50 \mathrm{ml})$ at room temperature. The final mixture was refluxed at $70^{\circ} \mathrm{C}$ temperature. The solvent was removed under reduced pressure at $70^{\circ} \mathrm{C}$ using a rotary evaporator and the resulting cream solid washed with methanol

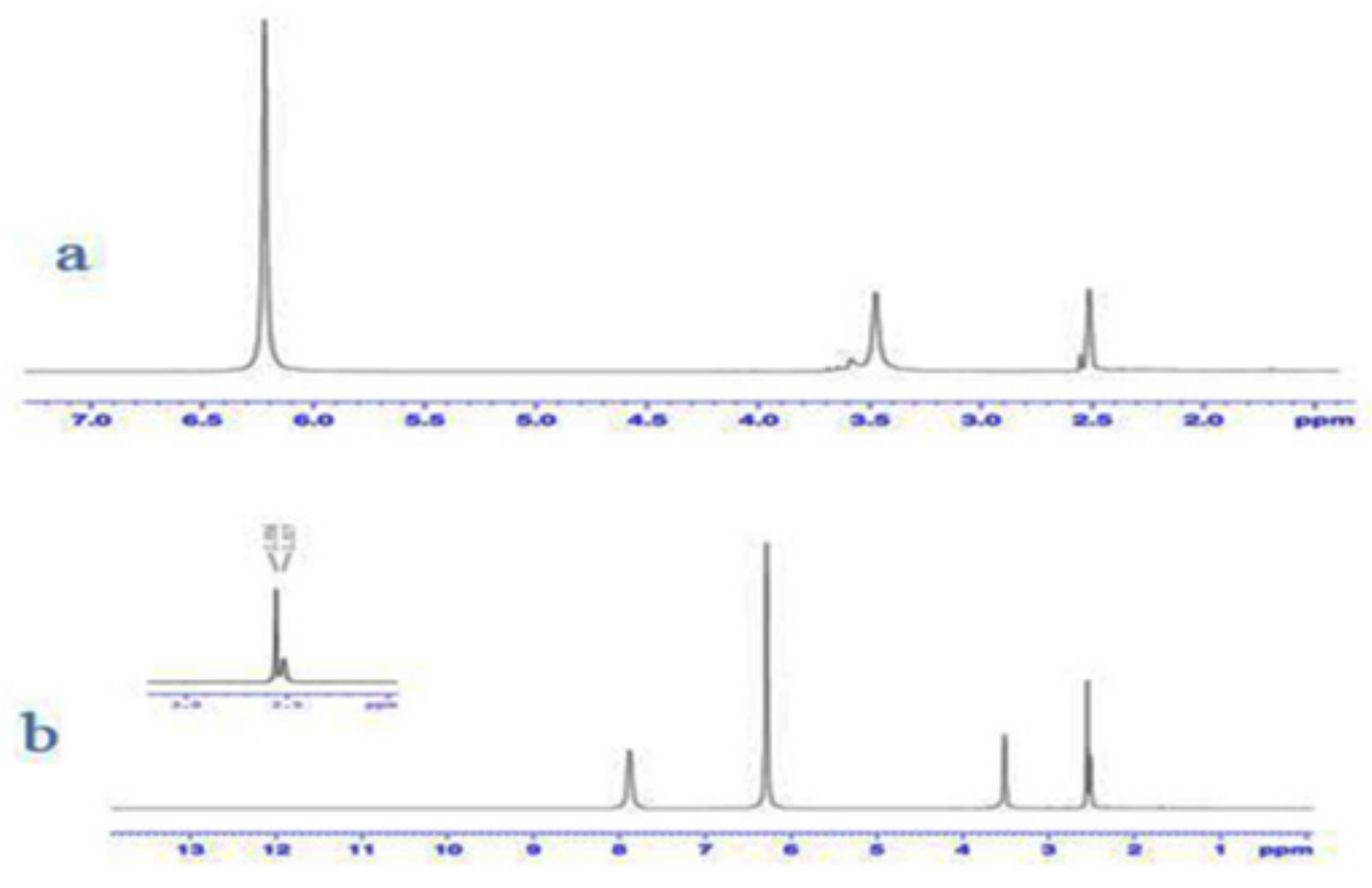

Fig. 3: H-NMR spectrum of a: $G_{0.5,}$ b: $G_{1}$ 
and dried under vacuum $\left(10^{-1} \mathrm{~mm} \mathrm{Hg}, 80^{\circ} \mathrm{C}\right)$ to give the pure product (12 $\mathrm{g}, 80 \%$ ) (Fig 1).

Spectral characterization of $\mathrm{G}_{0.5}$ has been determined as follows: FT-IR $\left(v_{\max } / \mathrm{Cm}^{-1}\right): 1651(\mathrm{C}=\mathrm{O})$; ${ }^{1} \mathrm{H}-\mathrm{NMR}\left(\mathrm{CDCl}_{3}\right) \delta_{\mathrm{H}}: 6.222(3 \mathrm{H}, \mathrm{a}), 3.60(9 \mathrm{H}, \mathrm{d})$, $3.475(6 \mathrm{H}, \mathrm{b}), 2.515(6 \mathrm{H}, \mathrm{c}) ;{ }^{13} \mathrm{C}-\mathrm{NMR}\left(\mathrm{CDCl}_{3}\right) \delta_{\mathrm{C}}$ : 172.61(d), 167.66(a), 51.80(e), 40.78(b), 39.04(c); m/z:384, 341, 294, 281,252,212,126,110,86,68.

\section{Preparation of amine terminated gruop $\mathbf{G}_{1}$}

A solution of precursor $\left(G_{0.5}\right) ;(10 \mathrm{~g})$ in DMSO $(50 \mathrm{ml})$ was carefully added to a vigorously stirred solution of melamine $(9.84 \mathrm{~g})$ and sodium

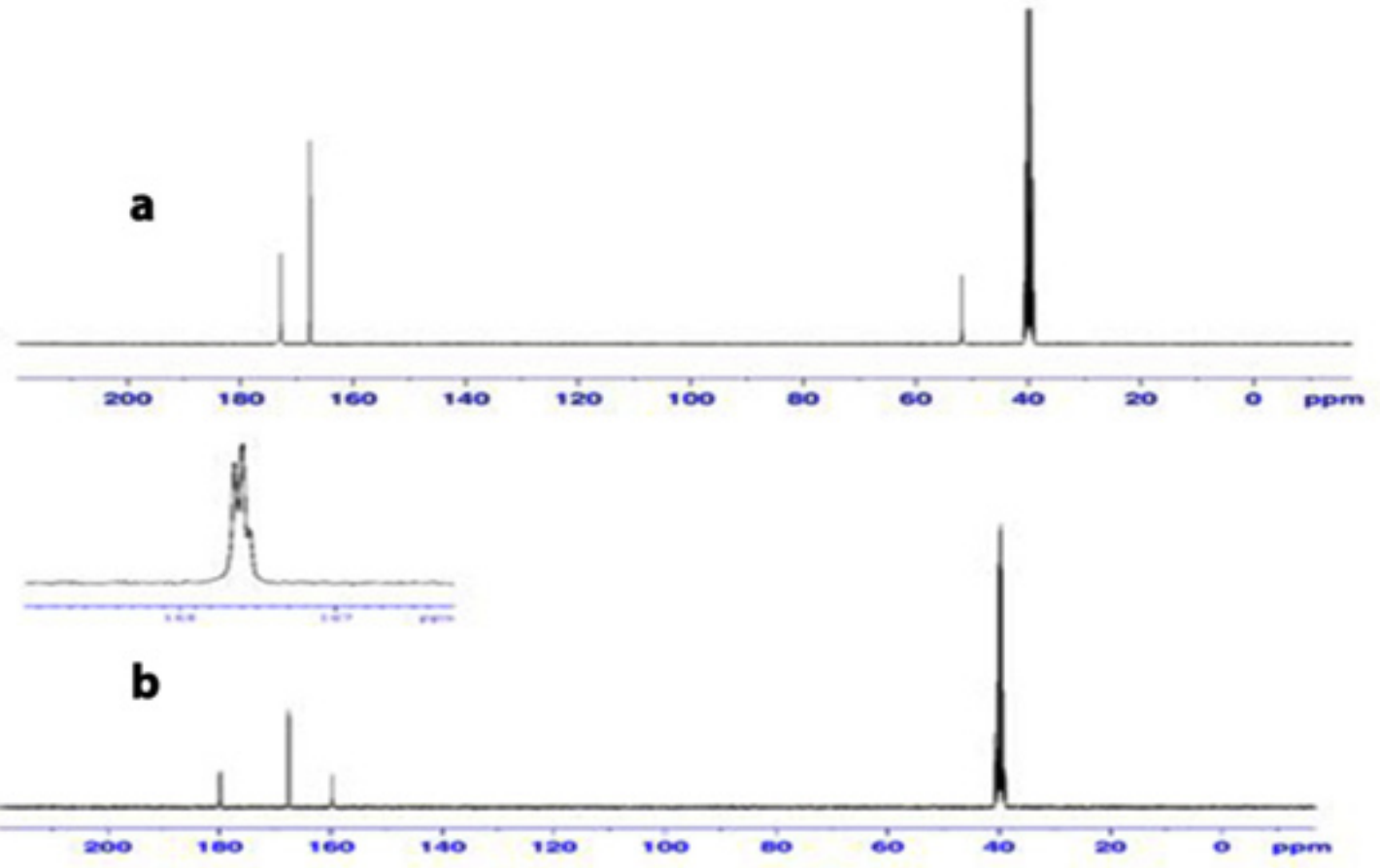

Fig. 4: ${ }^{13}$ C-NMR spectrum of a: $G_{0.5}$, b: $G_{1}$
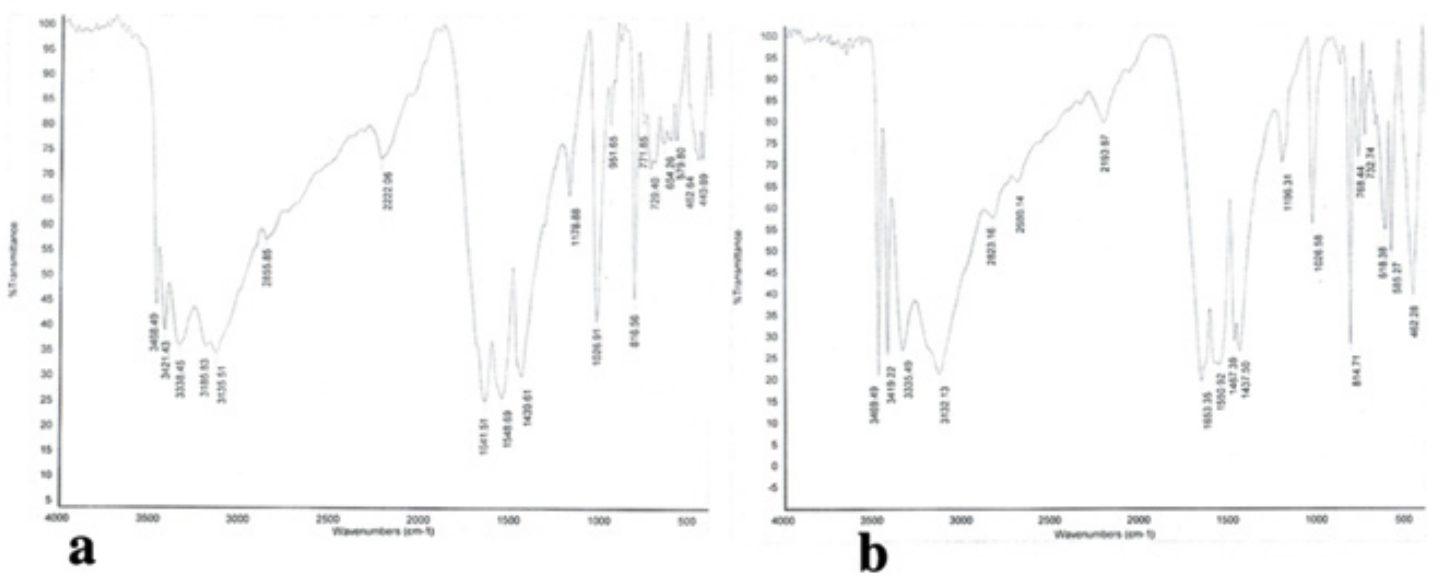

Fig. 5: FT-IR spectrum of a: $G_{0.5}$, b: $G_{1}$ 
azide $(1.32 \mathrm{~g})$ in DMSO $(50 \mathrm{ml})$ at $25^{\circ} \mathrm{C}$. The mixture was stirred for $96 \mathrm{~h}$ at $70^{\circ} \mathrm{C}$. The solvent was removed under reduced pressure at $70^{\circ} \mathrm{C}$ using a rotary evaporator and the resulting cream solid washed with methanol and dried under vacuum $\left(10^{-1}\right.$ $\left.\mathrm{mm} \mathrm{Hg}, 80^{\circ} \mathrm{C}\right)$ to give a pure product $(17 \mathrm{~g}, 85 \%)$ (Fig 2).
Spectral characterization of $\operatorname{PAMAM}\left(G_{1}\right)$ is demonstrated as follows

FT-IR $\left(\mathrm{U}_{\max } / \mathrm{Cm}^{-1}\right)$ : 1640(C=O), $3200\left(\mathrm{NH}_{2}\right)$, $3400(\mathrm{NH}) ;{ }^{1} \mathrm{H}-\mathrm{NMR}\left(\mathrm{CDCl}_{3}\right) \delta_{\mathrm{H}} ; 7.921(3 \mathrm{H}, \mathrm{d})$, $6.287(15 \mathrm{H}, \mathrm{a}, \mathrm{e}), 3.517(6 \mathrm{H}, \mathrm{b}), 2.517(6 \mathrm{H}, \mathrm{c}) ;{ }^{13} \mathrm{C}-$ $\mathrm{NMR}\left(\mathrm{CDCl}_{3}\right) \delta_{\mathrm{C}}: 180.15(\mathrm{f}), 167.64(\mathrm{~d}), 167.55($
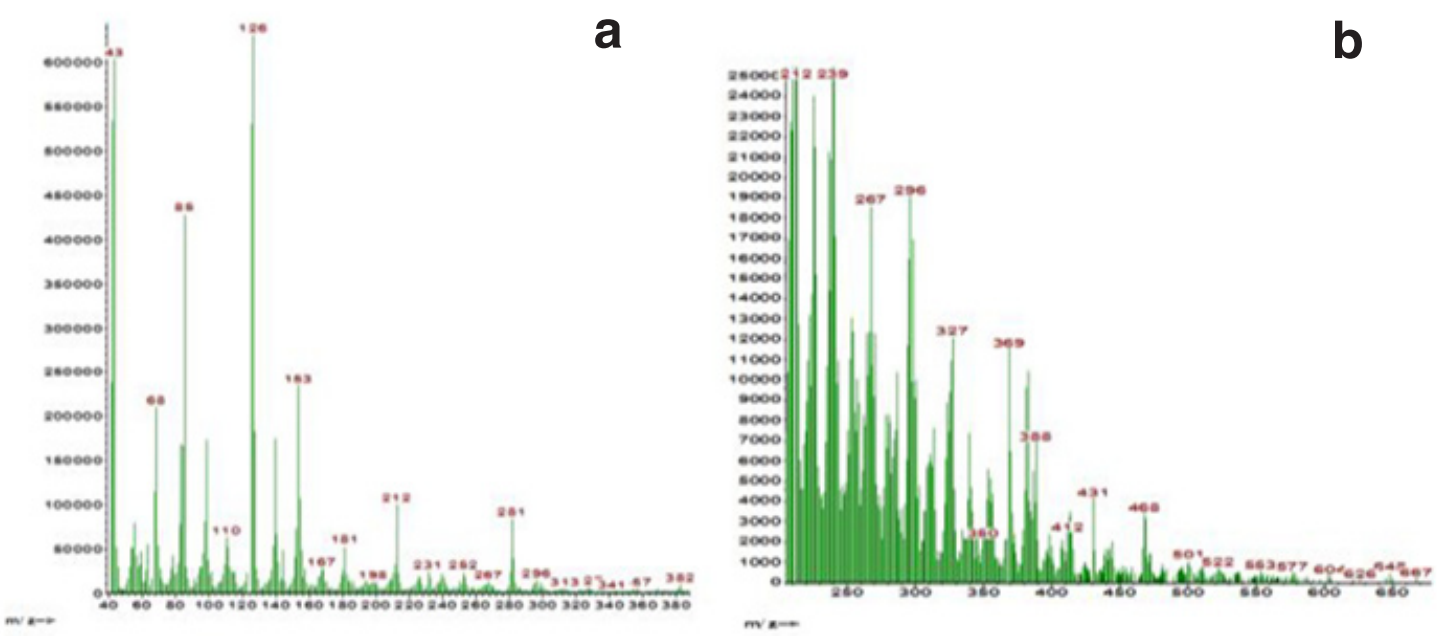

Fig. 6: Mass spectrum of a: $G_{0.5}$, b: $G_{1}$
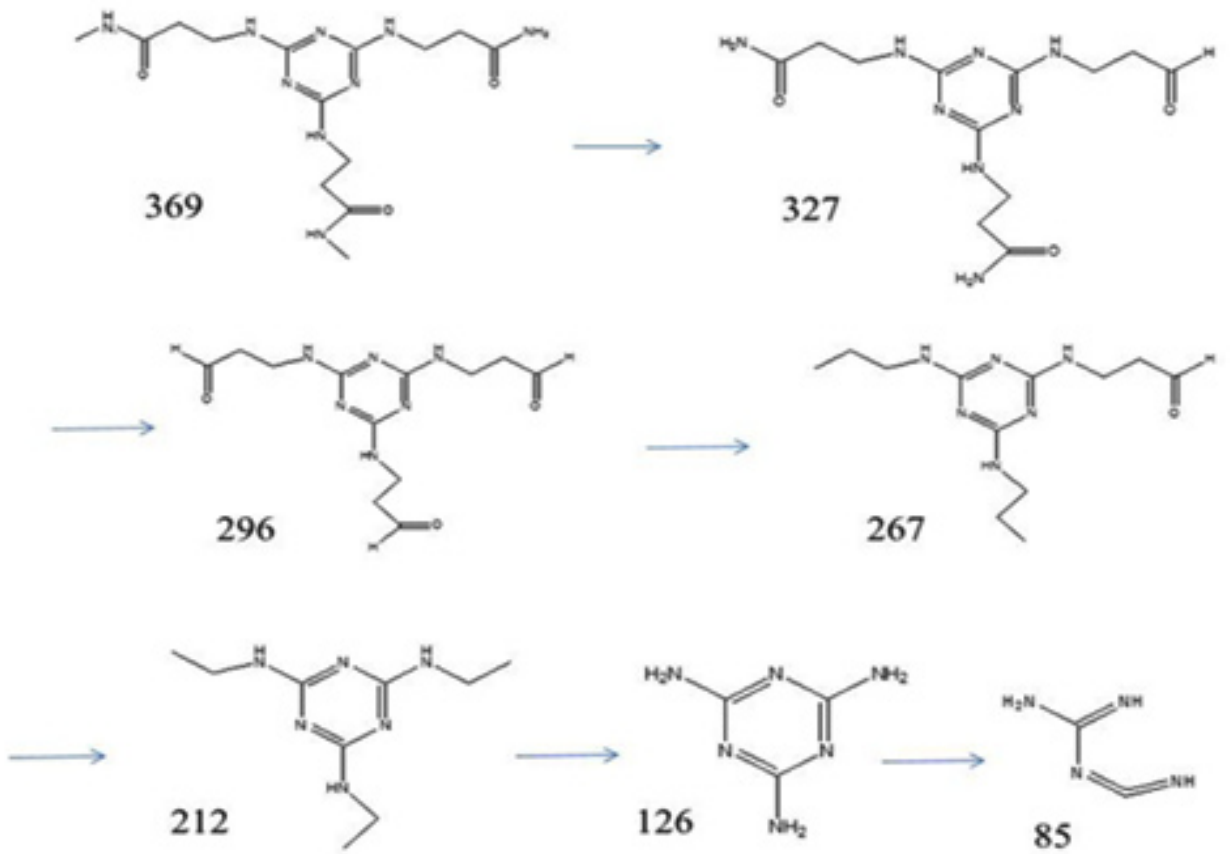

Fig. 7: $\mathrm{m} / \mathrm{z}$ peak of $G_{1}$ 
a), 158.98(e), 40.73(b), 38.99(c); m/z: 667, 650, 638, 577 ,468, 431, 381, 369, 340, 327, 296, $212,126,85$.

\section{RESULTS AND DISCUSSION}

Experimental data are according to this fact that the various generation of denderimers have been synthesized.

${ }^{1} \mathrm{H}$ and ${ }^{13} \mathrm{C}$ NMR spectra were also fully consistent with the proposed structures. It is interesting to note that the peaks corresponding to the aromatic ring were perturbed by the presence of the dendritic branching.

H-NMR data analysis also confirmed the synthesis of dendrimers in which hydrogen of $\mathrm{NH}$ were appeared at $6.222 \mathrm{ppm}$ and hydrogen of metoxy groups at $3.60 \mathrm{ppm}$ in $G_{0.5}$ while hydrogen of amino groups have been at $6.287 \mathrm{ppm}$ and hydrogen of amido groups at $7.921 \mathrm{ppm}$ for $G_{1}$ (Fig 3).

We expected to observe peaks related to $\mathrm{NH}$ and $\mathrm{NH}_{2}$ groups in higher fields but they showed about 2 ppm shift toward low field which indicates hydrogen bond formation in dendrimer structure.

${ }^{13} \mathrm{C}-\mathrm{NMR}$ data analysis also confirmed the synthesis of dendrimers in which carbonyl functional groups $(C=O)$ were appeared at $172.61 \mathrm{ppm}$ and carbone of metoxy groups at $51.80 \mathrm{ppm}$ in $G_{0.5}$ and carbone of amido groups have been at $167.64 \mathrm{ppm}$ and carbone of aromatic ring at 158.98, 180.15 ppm for $G_{1}$ (Fig 4).

FT-IR analysis for different generations indicates the presence of metoxy groups in $G_{0.5}$ which is replaced by amino groups in $G_{1}$ (Fig 5 ).

Considering frequency depletion of carbonyl group in IR spectrum it can be concluded that hydrogen formed.

Characterisation of the novel dendritic was achieved using all standard techniques. Mass spectrometry, which is particularly important for dendritic systems, was performed using electrospray ionisation, and the ions were observed for $G_{0.5}$ and $G_{1}$ no significant fragment peaks or impurities were present. The isotope distributions observed

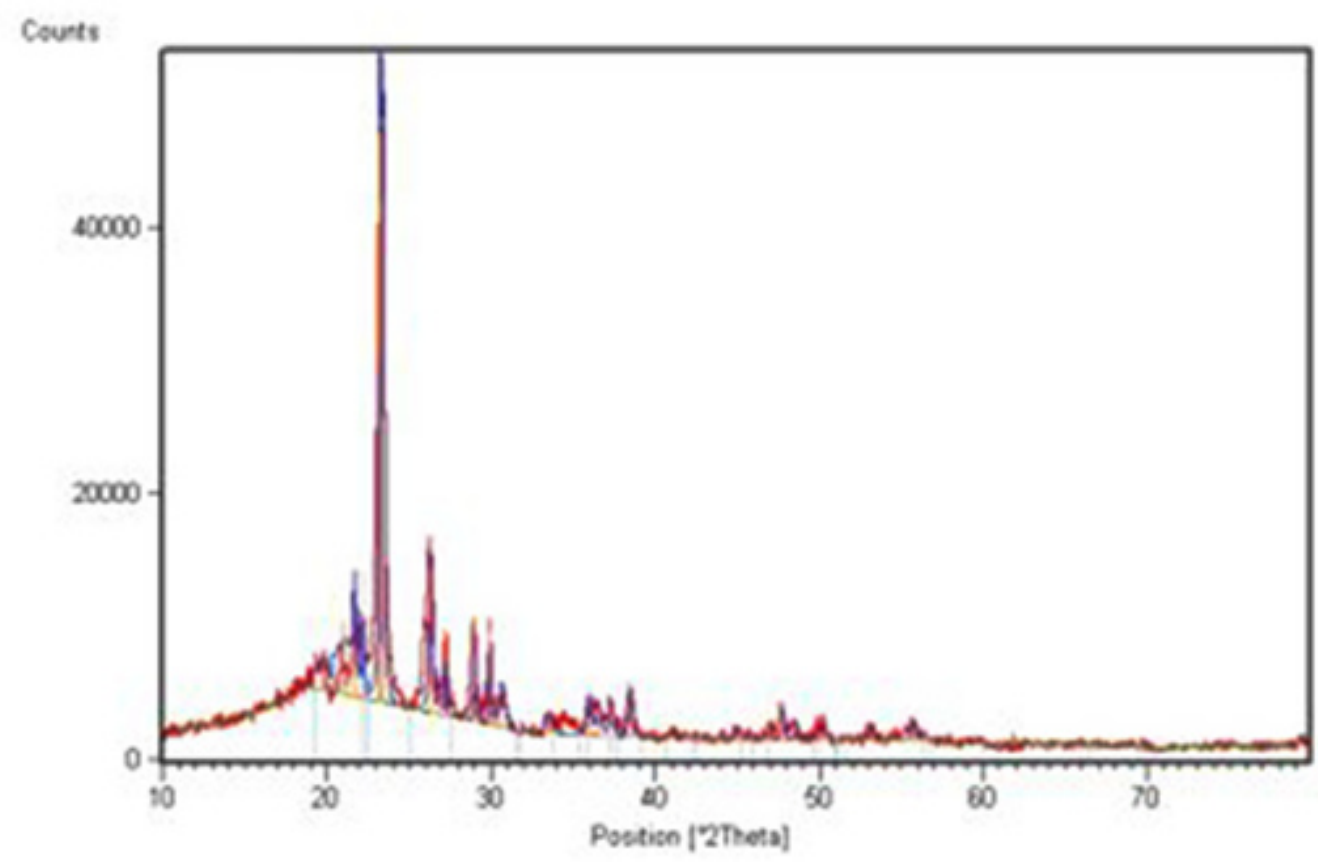

Fig. 8: XRD analysis 
for the mass spectral ions of the larger molecules were consistent with data calculated from isotopic abundances.

According to mass spectrum (Fig 6, a) of $G_{0.5}$, there are four distinct $\mathrm{m} / \mathrm{z}$ peaks: at $\mathrm{m} / \mathrm{z} 252$ for losing three esteric groups from the dendrimer terminal, at $\mathrm{m} / \mathrm{z} 212$ for losing three methyl groups from the terminal of $\mathrm{m} / \mathrm{z} 252$, at $\mathrm{m} / \mathrm{z} 126$ for producing core melamine molecule and at $\mathrm{m} / \mathrm{z} 58$ for opening the melamine ring. $\mathrm{M} / \mathrm{z}$ peak of $G_{0.5}$ at 382 has appeared very low which shows the instability of synthesized dendrimer.

At $G_{1}$ (Fig 6,b), $\mathrm{m} / \mathrm{z}$ peak at 667 is similar to $G_{0.5}$ and is very low which shows its instability at reaction condition and $\mathrm{m} / \mathrm{z}$ peak of melamine ring opening has appeared at 468. Other distinct peaks have appeared at $\mathrm{m} / \mathrm{z} 369,327,296,267,212,126$ and 85 which are illustrated in (Fig 7).

According to XRD spectrum and Scherrer's formula, synthesized dendrimer of generation 1 has nano dimension (86 nm) (Fig 8).
Considering the widening of IR spectrum over $3000 \mathrm{~cm}^{-1}$ and downfield shift of NMR peaks (4 ppm to over 6 ppm) for $\mathrm{NH}$ and $\mathrm{NH}_{2}$ it can be concluded that the synthesized dendrimer is a supramolecule.

With these observations it can be speculated that synthesized dendrimer participates in hydrogen bonding through oxygen and nitrogen atoms.

\section{CONCLUSION}

According to spectral evidence it can be concluded that dendrimer generation 0.5 has been synthesized through reaction of melamine as core and methyl acrylate and then it reacted with added melamine monomer and dendrimers generation 1 have been obtained with amine terminal and also the formation of supramolecule dendrimer can be assured.

\section{ACKNOWLEDGMENTS}

We are thankful to sophisticated test and instrumentation center BuAli Research Institute and Khorasan Science and Technology Park (KSTP) of Mashhad.

\section{REFERENCES}

1. Buhleier, E.; Wehner, W.; Vögtle, F. Synthesis. 1978, 2, 155-158.

2. Feuerbacher, N.; Vögtle, F. Top Curr Chem. 1998, 197,1-18.

3. (a) Tomalia, D.A.; Baker, H.; Dewald, J.R.; Hall, M.; Kallos, G.; Martin, S.; Roeck, J.; Ryder, J.; Smith, P. Polym J (Tokyo). 1985,17, 117132. (b) Potkin, V.I.; Shcharbin, D.; Denisov, A.A.; Paschkevich, S.G.; Bryszewska, M.; Petkevich, S.K.; Kletskov, A.V.; Lapotko, D.O.; Kazbanov, V.V. Cellular \& Molecular Biology Letters. 2014, 19(2), 243-248.

4. De Brabander-van den Berg, E.M.M.; Meijer, E.W. Angew Chem Int Ed Engl. 1993, 32,1308-1311.

5. Mansfield, M.L. Macromolecules. 1993, 26 (15), 3811-3814.

6. For general reviews of supramolecular dendrimer chemistry see: (a) Narayanan, V.V.;
Newkome, G.R. Top. Curr. Chem. 1998,197, 19-77. (b) Smith, D.K.; Diederich, F. Top. Curr. Chem 2000, 210, 183-227. (c) Zimmerman, S.C.; Lawless, L.J. Top. Curr. Chem. 2001, 217,95-120. (d) Emrick, T.; Fre'chet, J.M.J. Curr. Opin. Colloid Interf. Sci. 4 1999, 15-23. (e) Zeng, F.W.; Zimmerman, S.C. Chem. Rev. 1997, 97, 1681-1712.

7. Lehn, J.M. VCH, Weinheim 1995.

8. Atwood, J.L.; Davies, J.E.D.; MacNicol, D.M.; Vögtle, F.; Lehn, J.M. Pergamon, Oxford, 1996.

9. Philp, D.; Stoddart, J.F. Angew. Chem. Int. Ed. Engl. 1996, 35, 1155-1196.

10. (a) Gale, P.A.; Steed, J.W. Wiley, New York, 2012. (b) Fouquey, C.; Lehn, J.M.; Levelut, A.M. Adv. Mater. 1990, 2(5), 254-257.

11. Gennady, V.O.; David, N.R.; Willem, V. Angewandte. Chemie International Edition. 
2007, 46(14), 2366-2393.

12. Sijbesma, R.P.; Meijer, E.W. Curr. Opin. Colloid Interface Sci. 1999, 4, 24-32.

13. Brunsveld, L.; Folmer, B.J.B.; Meijer, E.W.; Sijbesma, R.P. Chem. Rev. 2001, 101(12), 4071-98.

14. Abraham, M.H. Chem. Soc. Rev. 1993, 22 ,73-83.

15. (a) Vale'rio, C.; Fillaut, J.L.; Ruiz, J.; Guittard, J.; Blais, J.C.; Astruc, D.J. Am. Chem. Soc. 1997, 119(10) ,2588-2589. (b) Vale'rio, C.; Alonso, E.; Ruiz, J.; Blais, J.C.; Astruc, D. Angew. Chem. Int. Ed. 1999, 38 (12) ,17471751. (c) James, T.D.; Shinmori, H.; Takeuchi, M.; Shinkai, S. Chem. Commun. 1996, 705706. (d) Albrecht, M.; Gossage, R.A.; Spek,
A.L.; van Koten, G. Chem. Commun. 1998, 1003-1004. (e) Boas, U.; Sontjens, S.H.M.; Jensen, K.J.; Christensen, J.B.; Meijer, E.W. Chem Bio Chem 2002, 3, 433-439.

16. (a) Seto, C.T.; Whitesides, G.M. J.Am. Chem. Soc. 1990, 112, 6409-6411. (b) Liu, K.; Xu, Z.; Yin, M. Polymer Science. 2015, 46 , 25-54. (c) Yin, Y.; Dong, Z.; Luo, Q.; Liu, J. Polymer Science. 2012, 37 (11), 1476-1509.

17. Whitesides, G.M.; Mathias, J.P.; Seto, C.T. Science. 1991, 29; 254 (5036), 1312 1319.

18. Li, X.; Chin, D.; Whitesides, G.M. J. Org. Chem. 1996, 61 , 1779-1786.

19. Briançon et al. Studia Geotechnica et Mechanica. 2005, $27(1-2)$,22-32. 